\title{
Student Perceptions on Collaborative Writing in a Project-based Course
}

\author{
Tanju Deveci
}

\begin{abstract}
Department of English, College of Arts and Sciences, The Petroleum Institute, Khalifa University of Science and Technology, Abu Dhabi, the United Arab Emirates
\end{abstract}

Copyright $\odot 2018$ by authors, all rights reserved. Authors agree that this article remains permanently open access under the terms of the Creative Commons Attribution License 4.0 International License

\begin{abstract}
The traditional view that writing is an individual activity often translates into the teaching of it as an individual task. Rarely do students engage in extensive dialogue with their peers when writing. However, much writing in the workplace takes place in collaboration with others. Although, on the surface, many authors may not seem to write with others collaboratively, the truth is that they engage in intensive intrapersonal community affected by interpersonal communication. They also communicate with them through incorporating ideas from other authors and by following requirements set by publishers and teachers. Collectively, these entail that writing instruction at college be tailored towards students' current and future needs. In addition, the collection of student perceptions of such an instructional design is necessary for curriculum designers and teachers to better cater to student needs. It is also useful to identify student perceptions related to gender in gender-segregated learning environments commonly encountered in Arab nations. Motivated by these factors, this study investigated sixty-four first-year Emirati university students' (thirty-one males \& thirty-three females) views on collaborative writing in a Project Based Learning (PBL) class on a gender segregated campus. Quantitative and qualitative data were collected using a survey and a discourse completion task. Results revealed that the students believed that collaborative project writing was compatible with the Emirati culture. As well, their overall satisfaction with their collaborative writing experience was positive. They were particularly happy that it contributed to general skills that included the use of technology and critical thinking skills. They were also positive about its effects on their English language and teamwork skills. Promotion of active learning and innovation was also agreed upon as a positive attribute of collaborative project writing. Results also showed that the female students were overall more content with their experience, with particularly positive opinions about its effects on English and teamwork skills. Results are discussed, and recommendations are made to enhance
\end{abstract}

learning environments compatible with the principles of collaborative learning.

Keywords Collaborative Learning, Collaborative Writing, Team-work, Student Satisfaction

\section{Introduction}

Sociologists and psychologists, among others, recognize that humans are social beings with a need to belong to a group and/or an institution. This need has both biological and social roots [1]. As far as the former is concerned, it is essential for us to exist in safety, which often requires the presence of others around us. The latter, on the other hand, allows us to achieve mental growth. From the standpoint of education, our interaction with others helps us to organize our thoughts, reflect on our understanding, and find gaps in our reasoning [2]. Added to this is Vygotsky's (1978) [3] assertion that our cognitive development is reinforced in sociocultural contexts where we interact with others who are more skilled than ourselves, be it a teacher or a peer. Collectively, these have led many educational institutions to embrace approaches that lend themselves to consideration of the social nature of learning.

This has also affected the instruction of writing, which often used to be considered an individual endeavor. One approach to teaching writing skills through social interaction is "collaborative writing", which has gained considerable support in recent years. Storch (2016) [4, p. 387] provides a simple definition of it: "the production of a text by two or more writers." What distinguishes it from other types of writing like peer response activities is that interaction is not limited to the pre-writing or post-writing stages, but engages student partners in all stages of writing from decision-making to construction and editing of the text. In this sense, Storch (2016) [4] also warns that it 
differs from student projects where students "co-contribute" rather than "co-construct" a text. Influenced by such differences in approaches to teaching writing, research has mainly focused on stand-alone collaborative writing activities such as dictogloss ${ }^{1}$ with the aim of confirming their positive effects on academic performance. Little is yet known about "collaborative project writing", which, in my context, includes both collaboration and co-contribution to the construction of a project paper within a PBL environment where much of student work is completed in teams as well as some individually. Although scholars have often argued for the benefits of collaborative and co-contributive nature of PBL for knowledge and skills building [5] [6], much has been narrated from the teacher perspective supported by research findings relative to the process and results. Although concerns about its drawbacks are also expressed, these, too, are often related to faculty perceptions, vaguely reflecting student views. Also, Dobao and Blum [7] note that investigations conducted to identify student perceptions on collaborative writing have often focused on pair-work, without much attention to writing composed in teams/groups. This study aims to expand the existing body of knowledge on students' evaluations of their learning experiences regarding collaborative project writing in the context of a PBL-based English course. Students' reflections on and perceptions of their collaborative project writing experiences are of particular importance since these are the factors that often determine their approaches to learning at large [8] and provide the faculty with insight into ways in which they could better cater to students' needs and preferences.

\section{Literature Review}

\subsection{Collaborative Writing}

\subsubsection{Definition of Collaborative Writing}

There are a varitey of definitions of the term "collaborative writing". A simple definition is given above [4]. Another definition is offered by Howard [9, p. 54] : "an assignment in which students work together from start to finish, producing a single paper from the group." This definition fits the teaching context in which the current study was undertaken where students are assigned a long-term project culminating in a team-produced report at the end of the term. (This is described in detail in a subsequent section.) Collectively, these definitions are based upon the notion of individual students' engagement in pair/group work in composing a text or a project paper.

There is also the argument that all writing is

1 A dictation activity based on the principles of collaborative writing. collaborative since writers continually refer to the works of other writers, either through the use of in-text citations or of a standard format [10]. In this sense, writers engage in interpersonal communication, which can take a variety of forms. Any interpersonal communication for writing purposes is, in essence, collaborative. This is congruent with the notion of "social turn" in composition studies, according to which "writing is always the product of a dialogue with self and others...[and there is value in] prewriting, drafting, and revising by encouraging students to do these activities together" [11, p. 3]. This fits the contenxt of the current study since students are often required to read scholarly papers to familiarize themselves with their research topics, evaluate authors' stance, and identify a gap in the literature. They then cite relevant information in their reading when writing individual and team assignments, both of which are central parts of the team project paper. They are also required to follow submission guidelines which include format specifications decided by the instructor.

It is the broader concept of "collaborative learning" that has given way to the development of collaborative writing. Collaborative learning has its roots in the social constructivist view of learning influenced by eminent educators such as Vygotsky, Piaget, and John Dewey. This view of learning postulates that students' engagement in small group discussions increases motivation and builds a deeper understanding of content matter, thereby advocating self-regulation skills [12]. It embodies a variety of educational approaches that lend themselves to joint intellectual efforts among students as well as between students and teachers [13].

In these learning environments, teachers' role shifts from transferring their own knowledge to students to facilitating the learning process through active engagement of students in all stages of the lesson. To this end, teachers provide "rich environments, experiences, and activities for learning by incorporating opportunities for collaborative work, problem solving, authentic tasks" [14, p. 253]. This is done with a view towards self-directed learning which enables students to diagnose their learning needs, formulate learning goals, identify required resources for these, choose and implement appropriate strategies for learning, and evaluate learning outcomes [15, p. 18].

\subsubsection{Benefits and Challenges of Collaborative Writing}

There is overwhelming agreement that collaborative writing offers a variety of cognitive and social benefits to students. In terms of the former, it enables students to assume responsibility for their own learning, learn how to learn, and develop critical thinking skills when analyzing texts, arguments and composing their own papers [10]. Due to the increased interaction and negotiation in the process, students improve their vocabulary, understanding of text coherence, and gain new ideas and perspectives [16] Collaborative writing has also been shown to help students 
narrow down information for establishing clarity in writing [17], which requires them to exercise critical thinking skills. They can transfer these skills to other subjects and contexts outside of school, which contributes to the students' development of lifelong learning skills.

Another benefit is related to the immediate audience and instant feedback which the writers receive. This encourages them to compose their writing with a specific audience in mind and to be clear with their messages (Porto cited in Grief [18]). In terms of the latter, Dale (cited in Speck [10]) states that collaborative writing teaches students cooperation and negotiation skills, which are essential elements of teamwork at the workplace. Speck [10] notes that collaborative writing projects help university students acquire skills they need as future writers in business, government, and industry where much writing is done in collaboration with others. He states, "Students can learn how to work with people, how to compromise effectively, [and] how to value differences" $[10$, p. 22]. Research has shown that university students' collaborative writing experience makes them more accountable not only for their own learning but also for their peers' [17]. They develop a sense of responsibility for sharing their expertise and newly-acquired information with their peers. They are also encouraged to negotiate successfully in face-to-face as well as online platforms. Taken together, they point to the potential of collaborative writing for promoting excellence and harmony in group/team work.

However, there are arguments that collaborative writing may not always be feasible. These arguments rest on the following assumptions. First, there is the concern that it is time-consuming; it takes time to learn how to implement the writing process in the classroom and evaluate the learning process and student outputs [10]. Also, many classes are arranged for lectures limited to fifty-minute sessions with little to no opportunity to allow student-student interaction and the hearing-out of multiple perspectives [13]. Added to this is the reality that the physical set-up of many lecture rooms do not permit students to work in pairs, let alone in teams or groups. In addition, not everyone may be comfortable about having to make compromises regarding teaching orientations they feel strongly about, causing many professors to stick to the conventional way of delivering lectures [18]. Among other concerns expressed regarding the potential barriers to students' willingness to collaborate with others are [19]: a) those who are individualistic may refrain from working with others, b) weaker students may be overpowered by stronger students, and c) one member of the group may take too much responsibility, leaving others with little to do.

\subsubsection{Collaborative Writing and Project Based Learning}

Project Based Learning has its roots in John Dewey's notion of experiential learning, which underscores the importance of meaningful learning experiences. One definition of it is: "a systematic teaching method that engages students in learning knowledge and skills through an extended inquiry process structured around complex, authentic questions and carefully designed projects and tasks" [20, p. 4]. In this way, it engages students in learning by doing; therefore "increases student motivation while improving [their] problem-solving and higher-order thinking skills" [21 p. 16]. Student teams, comprised of individuals with a variety of skills, are assigned tasks to complete a final product [22], which, in the context of this study, is a research project report.

Collaborative project writing in a PBL environment supports development of the students' skills as independent writers, "who use critical thinking skills, writing strategies, applications and conventions correctly to communicate their thoughts and ideas effectively" [23, p. 4]. Involved in a challenging scientific/academic writing task, students are provided the opportunity to interact with other students (as well as with the instructor and the authors whose works they read) who likely have varying degrees of literacy skills. However, it is essential that every team member contribute to the writing of the project. There may be instances when the team divides the work in parts; however, each member should still ask for other members' involvement and commitment to their individual parts [24]. Only in this way will the group be able to see the whole picture and develop ownership of the project as a whole.

The holistic learning environment established by PBL creates opportunities for all involved to make informed choices about learning/teaching according to evolving situations, allowing students to develop according to their cognitive and psychological readiness [5]. For example, a student who is not conceptually ready to incorporate his reading into a team literature review may be aided by a team meeting where members discuss their texts to identify themes and patterns. This gives the student an opportunity to see the bigger picture, which helps "the conceptually not-ready student" comprehend his/her own text better. In this way, the team becomes more able to "develop the ability to synthesize output such as in group literature reviews or discussion sections of reports" [5, p. 15]. In our previous research, we identified some evidence that interaction in a small team discussion, similar to the one described above, has significant potential to influence students' academic reasoning in the form of synthesized argumentation in their team-written project report [6].

\section{Research Context, Rationale for the Study, and Research Questions}

This research was conducted in the context of Khalifa University of Science and Technology (KUST). As a 
support program, the Department of English offers two mainstream courses, one of which is English 112 (ENGL112) where this study was undertaken. ENGL112 is essentially based on the principles of PBL, engaging students in extensive writing experience both individually and in teams. The PBL nature of the course provides a holistic approach to learning with a view towards learning as a social activity [25]. Students are often asked to reflect on their experience in different venues such as reflective writing assignments. At the end of the term, students are also required to respond to a survey relative to their experiences of working in teams. Although some of the questions in this survey are related to their collaborative report writing experience, these are rather general unless students choose to elaborate on their responses, which hardly any student opts to do. Questions in the survey do not enquire about the effects of the collaborative project writing experience on individual assignments or on the individual students' academic performance at large. This leaves us with little insight into their actual feelings about the whole process, causing instruction to be evaluated mainly on the basis of teacher reflection. Given the proportion of collaborative writing in the course, I believe a more systematic, in-depth way of investigating student perceptions needs to be developed.

KUST, which was established upon the merger of three higher education institutions in Abu Dhabi, has three campuses. The Sas Al-Nakhl, where this research was undertaken, is the only gender-segregated campus. The university's plan is to have co-education on all three campuses. With a segregated educational background, the Petroleum Institute (PI) on the Sas Al-Nakhl campus may benefit from comparing student perspectives according to gender. Identification of the similarities and differences between male and female student perceptions on collaborative project writing is expected to inform adjustments to our future curriculum and teaching. This research can provide insight into other contexts similar to our own.

Also, as is mentioned at the beginning of the paper, comparatively more is known about stand-alone collaborative writing teaching activities. More studies of student experiences with collaborative project writing and its impacts on individual learning activities and assignments are called for in particular in $\mathrm{PBL}$ environments.

Motivated by these factors, this study sought to answer the following questions:

1. To what extent do students think collaborative project writing is compatible with their Emirati culture? Does their perception change according to gender?

2. What is their overall satisfaction level with the collaborative writing experience? Does it change according to gender?
3. What are their perspectives on different aspects of collaborative project writing? Do they change according to gender?

\section{Methodology}

\subsection{Respondents}

A total of 64 freshman students from my two English II courses during the fall of 2017 participated in this study. Of this number, $31(48 \%)$ were male and $33(52 \%)$ were female on segregated campuses. The students' ages varied between 19 and 21, with a mean age of 20 . All participating students were Emirati.

\subsection{Data-collection and Analyses}

For triangulation purposes, the research questions were answered through analysis of data from two sources applied to the students in the third and second last weeks of the course after the students had slightly more than a threemonth exposure to collaborative project writing experience. The two sources are described below.

A Collaborative Project Writing Satisfaction Scale: The scale in the format of a survey included three main sections: demographics, overall student satisfaction level with collaborative project writing, and factors affecting student satisfaction level.

The initial stage of development of the last section was based on my own six-year experience in teaching writing skills in a PBL environment as well as a literature review conducted for the purposes of this study. At this stage, I developed a draft document on the benefits and potential drawbacks of collaborative project writing. Then, for construct validity purposes, I shared the draft with two other instructors in the department with extensive, similar teaching background, and with another professor who teaches teamwork and collaborative writing skills to pre-service language teachers at another university. In constructing the scale, I included the items all the professors agreed upon. The newly developed scale was then piloted with a group of ten students - the result of which determined the final version. This resulted in a 29-item, five-point Likert-type scale with five sub-domains which are interdependent and often mutually inclusive: Active learning (5 items), Innovation (4 items), General skills (7 items), English language skills ( 7 items), and Team skills (6 skills).

The scale included both positive and negative statements. For the latter type, a reverse scoring is used in calculating students' satisfaction levels. The maximum score a student can get from the scale is 145 while the minimum is 29 . No cut-off points for the scale were considered for this study, although the higher scores from the scale reflected higher 
satisfaction levels. A score close to the first quartile (36) was considered as a low level of satisfaction, a score close to the second quartile (72.5) as average satisfaction, and a score close to the third quartile (109) was as fairly high degree of satisfaction.

Cronbach's alpha coefficient computed to assess the scale's reliability resulted in a value of 0.86 , indicating good reliability.

\section{B Discourse completion tasks}

The quantitative data from the survey were supplemented with qualitative data collected using two discourse completion tasks, which included two incomplete sentences. The students were asked to complete these individually during class time. The first one was, "I like collaborative project writing because ..." while the second one was, "I don't like collaborative writing because...." This data collection tool was administered to the students a week prior to the survey so as not to affect student responses. This section of data collection was voluntary. The students were reassured that their responses would be kept confidential, and that they were not required to write their names. Despite this, only 35 students completed this section of data collection instrument. Of this number, $24(69 \%)$ were female and $11(31 \%)$ were male.

I analyzed the student responses myself first to identify the emerging themes. After this, I had another colleague in the department do the same. The themes identified by each of us were compared for inter-coder reliability purposes. The inter-coder reliability, calculated using the formula of "number of agreements / (total number of agreements + disagreements) formula" [26], was found to be $88 \%$. We held a session during which we discussed the discrepancies and reached agreement on the results.

\section{Results}

\subsection{Quantitative Data from Survey}

The first research question asked the extent to which students thought collaborative project writing was compatible with their Emirati culture and whether or not their responses changed according to gender. The results for this question are summarized in Table 1.

Table 1. Compatibility of collaborative project writing with the Emirati culture

\begin{tabular}{|c|c|c|c|c|c|c|}
\hline & Min & Max & $\overline{\mathrm{x}}$ & $\mathrm{SD}$ & $\mathrm{t}$ & $\mathrm{p}$ \\
\hline $\begin{array}{c}\text { Total } \\
(\mathrm{N}=64)\end{array}$ & 1 & 5 & 4.38 & 0.79 & & \\
\cline { 1 - 4 } $\begin{array}{c}\text { Male Students } \\
(\mathrm{N}=31)\end{array}$ & 1 & 5 & 4.18 & 0.93 & & \\
\cline { 1 - 4 } $\begin{array}{c}\text { Female Students } \\
(\mathrm{N}=33)\end{array}$ & 3 & 5 & 4.54 & 0.61 & -1.6224 & 0.0548 \\
\hline
\end{tabular}

$\mathrm{p}<0.05$
Table 1 shows that the overall average for compatibility of collaborative project writing with the Emirati culture was 4.38 , which indicates a strong affirmative student perception. This result was similar for male and female students in that both were of the idea that there was relatively strong harmony between their collaborative project writing experience and local culture $(\bar{x}=4.18$ and $\overline{\mathrm{x}}=4.54$ respectively). Also, a t-test run to compare student scores revealed a lack of difference at a statistically significant level $(\mathrm{t}=-1.6224, \mathrm{p}=0.0548>0.05)$.

The second research question was related to students' overall satisfaction with their collaborative project writing experience and whether or not their satisfaction differed according to gender. Results for this question can be seen in Table 2 .

Table 2. Satisfaction with collaborative project writing experience

\begin{tabular}{|c|c|c|c|c|c|c|}
\hline & Min & Max & $\overline{\mathrm{x}}$ & $\mathrm{SD}$ & $\mathrm{t}$ & $\mathrm{p}$ \\
\hline $\begin{array}{c}\text { Total } \\
(\mathrm{N}=64)\end{array}$ & 1 & 5 & 3.92 & 0.93 & & \\
\cline { 1 - 5 } $\begin{array}{c}\text { Male Students } \\
(\mathrm{N}=31)\end{array}$ & 1 & 5 & 3.94 & 0.93 & \multirow{2}{*}{0.3868} & 0.3501 \\
\cline { 1 - 5 } $\begin{array}{c}\text { Female Students } \\
(\mathrm{N}=33)\end{array}$ & 2 & 5 & 3.89 & 0.95 & & \\
\hline
\end{tabular}

$\mathrm{p}<0.05$

As can be seen in Table 2, the students' average score for the extent to which they were satisfied with their collaborative project writing was 3.92 , which indicates a relatively high level of contentment despite some concerns. A similar result appeared for male and female students $(\bar{x}=3.94$ and $\bar{x}=3.89$ ), albeit a slight difference to the benefit of the former. However, the difference between the data sets was not statistically significant $(\mathrm{t}=0.3868$, $\mathrm{p}=0.3501$ ).

The third research question aimed to identify student perceptions of different aspects of collaborative project writing that affect their satisfaction level. Results are summarized in Table 3.

Table 3. Satisfaction with different collaborative project writing aspects

\begin{tabular}{|c|c|c|c|c|}
\hline & Min & $\operatorname{Max}$ & $\overline{\mathrm{x}}$ & SD \\
\hline General skills & 17 & 35 & 28 & 3.83 \\
\hline English language skills & 14 & 32 & 26 & 3.88 \\
\hline Team skills & 10 & 28 & 20 & 3.65 \\
\hline Active learning & 8 & 25 & 19 & 3.11 \\
\hline Innovation & 5 & 19 & 14 & 2.98 \\
\hline Total & 52 & 129 & 106.55 & 14.78 \\
\hline
\end{tabular}

As is seen in Table 3, the overall level of student satisfaction with collaborative project writing (as informed by its five sub-domains) was 106.55 , which is closer to the third quartile (109) calculated for the instrument. This score indicates a fairly high degree of satisfaction despite some hesitation. This score was mainly influenced by the students' positive perceptions of particular sub-domains, 
one of which is "general skills." The most significant contribution of collaborative project writing, according to the students, was related to this domain with an average score of 28 . The students believed that they learned how to use technology for writing purposes. General skills also included their use of critical thinking skills such as analysis, evaluation, and synthesis. This was followed by their thoughts about its effects on English language skills. The students felt that their collaborative project writing experience gave them the opportunity to learn grammar and vocabulary from each other. Albeit with a comparatively lower score, team skills were also thought to be affected positively by the students' engagement in collaborative project writing. This included conflict-resolution skills. On the other hand, the students' beliefs related to the effects of collaborative project writing on active learning was comparatively less optimistic, with an average score of 19. Similarly, the students were not very convinced that their collaborative proejct writing experience allowed for innovation. For this aspect, the overall average was 14 .

The third research question also asked whether or not student responses differed according to gender. Results are seen in Table 4.

It is seen in Table 4 that the female students' overall score was higher than that of the male students (110.86 vs. 102.1). The difference was also statistically significant $(t=-2.2414, p-0.0142<0.05)$. Table 4 also indicates that the female students' comparatively higher level of satisfaction with collaborative project writing was due to their higher scores for two sub-domains: English language skills and team skills. For the former, the average scores were 25 vs. 27 while for the latter, they were 19 vs. 20. The differences between the data sets were also at statistically significant levels $\quad(t=-1.6794, \quad \mathrm{p}=0.0490<0.05 ; \quad \mathrm{t}=-1.9936$, $\mathrm{p}=0.0252<0.05$ respectively).

On the other hand, the male and female students were in agreement in regards to their outlook on general skills, innovation, and active learning. This was despite slightly higher average scores for these domains to the benefit of the female students. Yet the results of the t-test computed to assess the degree of differences for each domain were negative $\quad(\mathrm{t}=-1.6194, \quad \mathrm{p}=0.0552>0.05 ; \quad \mathrm{t}=-1.5097$, $\mathrm{p}=0.0680>0.05 ; \mathrm{t}=-1.3802, \mathrm{p}=0.0862>0.05$ respectively).

Table 4. Comparison between genders

\begin{tabular}{|c|c|c|c|c|c|c|c|c|c|c|}
\hline & \multicolumn{4}{|c|}{$\begin{array}{l}\text { Male Students } \\
\quad(\mathrm{N}=31)\end{array}$} & \multicolumn{4}{|c|}{$\begin{array}{l}\text { Female Students } \\
(\mathrm{N}=33)\end{array}$} & \multirow[b]{2}{*}{$\mathrm{t}$} & \multirow[b]{2}{*}{$\mathrm{p}$} \\
\hline & Min & $\operatorname{Max}$ & $\overline{\mathrm{x}}$ & SD & Min & $\operatorname{Max}$ & $\overline{\mathrm{x}}$ & SD & & \\
\hline Active learning & 8 & 23 & 19 & 3.46 & 12 & 25 & 20 & 3 & -1.3802 & 0.0862 \\
\hline Innovation & 5 & 19 & 14 & 3.71 & 11 & 19 & 15 & 2 & -1.5097 & 0.0680 \\
\hline General skills & 17 & 35 & 27 & 4.6 & 21 & 34 & 29 & 3.2 & -1.6194 & 0.0552 \\
\hline English language skills & 14 & 31 & 25 & 4.6 & 17 & 32 & 27 & 3.4 & -1.6794 & 0.0490 \\
\hline Team skills & 10 & 26 & 19 & 4.2 & 14 & 28 & 20 & 3.1 & -1.9936 & 0.0252 \\
\hline Total & 52 & 127 & 102.1 & 17.16 & 90 & 129 & 110.86 & 11.04 & -2.2414 & 0.0142 \\
\hline
\end{tabular}

$\mathrm{p}<0.05$

\subsection{Qualitative Data from Discourse Completion Tasks}

Data collected through the discourse completion task also helped identify student views on the benefits of the students' engagement in collaborative project writing. The analysis of the qualitative data revealed the themes in Table 5, which were often based on the complementarity of skills.

Table 5. Benefits of collaborative project writing experience

\begin{tabular}{|c|c|c|c|c|}
\hline \multirow{2}{*}{ Benefits } & \multicolumn{2}{|c|}{ f } & \multicolumn{2}{c|}{ Total } \\
\cline { 2 - 5 } & Female & Male & 31 & 32 \\
\hline Editing & 22 & 9 & 29 & 30 \\
\hline Generation of ideas & 18 & 11 & 14 & 15 \\
\hline Work distribution & 8 & 6 & 14 & 15 \\
\hline Diversity of skills & 7 & 7 & 2 & 2 \\
\hline Leadership skills & 1 & 1 & 2 & 2 \\
\hline Awareness of vocabulary & 2 & 0 & 2 & 2 \\
\hline Awareness of others' cultures & 2 & 0 & 2 & 2 \\
\hline Preparation for future profession & 1 & 1 & 2 & 96 \\
\hline Total & 61 & 35 & & 96 \\
\hline
\end{tabular}


Table 5 shows that eight benefits were identified by 35 students (24 female and 11 male) who responded to the second data collection instrument. Of the total number of 96 frequencies of the benefits of collaborative project writing, the most frequently mentioned one was editing, which appeared 31 times (32\%) in the data. It is important to note that a significant number of these were expressed by the female students ( 22 vs. 9). They often referred to peer feedback as a contributing factor. In this way, it was felt that "team members fill each other's gaps in writing." Another student stated, "I can learn more by looking at other writing and learn from their grammar mistakes. If a student is very good in English language I think I have ability to learn from her how she writes a long sentence without mistakes."

The second most commonly mentioned benefit was related to the generation of ideas, which was detected in the female students' responses more often than in those of the male students (18 vs. 11). Generation of ideas helped students to be more creative. This appeared 29 times (30\%) in student responses. It was mentioned that sharing knowledge with others "brings new and fresh ideas to the table," and "make[s] the task more creative and easier to accomplish."

The third most commonly mentioned benefit was related to time management being positively affected by work distribution, which was present in 14 student responses (15\%). Similar to the previous ones, this benefit appeared in the female data set more commonly than in the male one, albeit a relatively lower difference between the two (8 vs. 6). Equal distribution of work helped them produce more in a shorter period of time. As a result, in the words of a female student, "it lessens what's on our table and reduces stress." Similarly, another male student remarked: "Working on writing as a team means having less weight on my shoulders, which is always a personal advantage."

Diversity of skills was another theme that occurred 14 times $(15 \%)$ in the data set, with an equal distribution between the male and female students. The variety in skills such as reading, organization, and computer allowed students to produce better quality work and learn from each other. One female student said, "[Muna's] reading skills definitely helped me to understand my own text better. In this way I was able to write better." Another female student indicated that the organizational skills of a team-member helped them identify the main ideas in different texts they read. On the other hand, the students' social skills were mentioned as a factor contributing to students' satisfaction with their collaborative project writing experience. This was mentioned by four female students. It was indicated that a female member's outgoing personality "melted the ice at the beginning of the course," helping the team to build more cohesive bonds. It was also mentioned by another female student that "because I have encouraging friends around me I have more self-confidence and more motivation to write."
Albeit with comparatively lower frequencies (2\%), leadership skills, increased awareness of vocabulary, enhanced awareness of others' cultures, and preparation for future profession were also among the cited benefits of collaborative project writing. In terms of leadership skills, one female student said, "I was chosen as the team-leader, and this helped me improve my skills of leading and guiding other students." Two other female students stated that by reading more able students' pieces they learned new academic vocabulary and different combinations of words. Similarly, two female students referred to their increased cultural awareness developed through interaction with other students. They stated that examples used in writing came from sub-cultures from within the country, enhancing their understanding of how their fellow students think. Lastly, two students (one male and one female) pointed out the skills they practice through the collaborative project writing will be useful when they start working as engineers. The male student said, "It appears engineers write a lot with others. This experience is preparing us for this when we graduate."

Data on the students' opinions on the negative aspects of their collaborative project writing experience were collected using a second discourse completion task. The analysis of the data revealed the themes in Table 6 below.

Table 6. Negative aspects of collaborative project writing experience

\begin{tabular}{|c|c|c|c|c|}
\hline \multirow{2}{*}{ Negative aspects } & \multicolumn{3}{|c|}{$\mathrm{f}$} & $\%$ \\
\cline { 2 - 5 } & Female & Male & Total & \\
\hline Clashing opinions & 9 & 6 & 15 & 23 \\
\hline Members' careless work & 7 & 4 & 11 & 17 \\
\hline Time management & 4 & 7 & 11 & 17 \\
\hline Overpoweredness & 4 & 5 & 9 & 14 \\
\hline Lack of language skills & 4 & 5 & 9 & 14 \\
\hline Different writing styles & 5 & 2 & 7 & 11 \\
\hline Personality clashes & 4 & 0 & 4 & 6 \\
\hline Total & 37 & 29 & 66 & 100 \\
\hline
\end{tabular}

As can be seen in Table 6, there were 66 instances of negative thoughts in student perceptions. Similar to the benefits, the female students were more vocal about their thoughts than the male students were ( 37 vs. 29). However, this time the differences between frequencies were significantly smaller. The most commonly occurring theme was clashing opinions, which was detected nine times in the female students' responses and six times in those of the male students, with a total percentage of $23 \%$. Both genders often mentioned that it was not always easy for them to convince their team-members to accept their ways of thinking. One female student said, "Because I sometimes have to stick with others' idea[s], I can't write my own thought and feelings." A similar concern was expressed by a male student: "I am forced to go with the others' idea [because of] which I can't produce any work." Another male student remarked, "They just like to write 
what they believe in rather than listening to the others and try[ing] to understand them. This will lead to the unsuccessful writing with less ideas and limited information." These feelings often resulted in frustration and lack of motivation.

Careless work and time-management problems each appeared in the data set 11 times $(17 \%)$. In the case of the former, which was detected seven times in the female and four times in the male data sets, it was often mentioned that certain members depended on others to produce work; therefore, they put a limited amount of effort into the project. One male student stated: "One team member depends on others too much ending up being lazy and putting all the work on us." Another male student referred to last minute work: "Some students don't do their work in a professional way (they write in the last few minutes), they don't care about others and the mark (careless)." In the case of the latter, the frequencies of which were opposite for the male and female respondents, the students often mentioned clashing schedules as a factor causing time-management problems. It was mentioned that it is a challenge to find common times for team members to get together. Due to this, they often complete their parts individually, and then one person assumes the responsibility to put things together. However, if one member has not done a careful job, much time is spent correcting the work. This, at times, results in late submission of the project. Some female students also mentioned social aspects of team work as a factor causing time-management problems. She said, "Distraction is created by talking and chatting about topics unrelated to the project we're currently working on."

As well, overpoweredness was another negative aspect detected nine times in the student responses (14\%), with almost an equal distribution between the female and male data sets (four \& five respectively). It was often mentioned that certain members tend to dominate the writing process, leading them to feel overpowered. It was often mentioned that those with a higher proficiency in English tend to impose their own style on the team. In the words of a female student, "Some girls who think they are perfect in writing think that whatever they say must be written no matter what." This leaves other students with little to no opportunity to improve their writing.

In conjunction with concerns about dominance, there also was the challenge of deficiencies in some students' language skills (14\%), which was mentioned by the male and the female students with almost the same frequencies. Student responses from both genders included remarks on some students' comparatively lower levels of English, limiting the overall quality of work produced. Worried about receiving a satisfying grade, these students were reluctant to give such students a big role in writing. They also mentioned that correction of weak students' parts often delayed work. Some male students in particular were also concerned that their peers received grades that they did not deserve.
Another theme was related to differences in student writing styles (11\%). Although comparatively less frequent, this theme was present in more of the female responses (five vs. two). The female students in particular stated that they were not happy to work with people who used a different writing style from their own. For some this was confusing, and for others it was demotivating.

Personality clashes were also mentioned as a factor that reduced their level of satisfaction with the collaborative project writing experience $(6 \%)$. This theme was detected only in four of the female student responses. It was mentioned that shy students often did not want to share their work with others, which created some tension between team-members. On the other hand, some other students who were outspoken were viewed as too blunt. Collectively, these differences created communication problems among the members, especially at the beginning of the term. However, it was also mentioned that as they got used to each other, the communication between them became less strained.

\section{Discussion}

The first research question aimed to identify students' perception of the compatibility of collaborative project writing with their local culture. Data revealed that the students had a fairly positive stance on this, although the female students' orientation towards this style of writing was slightly stronger. Overall, this result was expected. The Emirati culture is collectivist in nature, emphasizing interdependence of group members. The nature of collaborative learning - emphasizing each person's responsibility for his own as well as his peers' learning - is therefore, compatible with collaborative learning. And just as collaborative learning reinforces students' acquisition and development of social skills required for harmonious relationships, so does collaborative project writing. A collectivist approach to learning underscores cooperation among peers with a view towards ensuring group success [27]. In the case of this study, cooperation was essential since the participating students were to produce one collective report in partial fulfillment of the course requirements. Influenced by their upbringing and educational background in a collectivist culture, the students in this study had also been expected to be attracted to collaborative writing experiences. This supports the observation that students' preferences for instructional activities are determined - to a large extent-by their dominant cultural orientations [28].

The second research question was related to the students' overall satisfaction level with their collaborative project writing experience. The quantitative data for this question showed that they were generally quite content with their experience, if not completely happy. Considering the students' cultural background discussed above, this result 
might be expected. Undoubtedly instructional design suited to students' cultural background plays a key role in achieving the desired outcome. As Ndon [14] also highlights, the teacher needs to ensure that learning activities lend themselves to authentic tasks involving students in collaborative work and problem solving. A conflict between these and students' cultural orientation could result in disengagement from learning. Fortunately, the results for the second research question -as yielded by the quantitative data- indicate this was not the case in this study. The fact that the total number of positive remarks in the qualitative data (96) outnumbered that of negative remarks (66) may be thought to support this finding. Nonetheless, the co-existence of positive and negative remarks in the qualitative data -at times by the same students-indicates at least some skepticism about the total efficiency of their collaborative project writing experience. It is also important to note that out of 35 students who responded to this section of the data-collection instrument $24(69 \%)$ were female, which is significantly higher than the number of male students (31\%). Although the quantitative data showed that gender was not a determining factor in the students' overall satisfaction level with their collaborative writing experience, the higher number of positive responses from the female students compared to that of the male students (61 vs. 35) provides some indication that the female students may be more positive about their experience. However, it was also interesting to observe that it was the female students again who mentioned a higher number of the negative aspects (37 vs. 29). The female students' stronger tendency to express their thoughts, whether positive or negative, is contrary to the observation that female college students are not as outspoken as their male counterparts [29]. All in all, the quantitative data indicating a similarity between the two genders relative to their attitude towards collaborative project writing may not be supported by the qualitative data strongly. Nonetheless, the relatively lower number of students providing qualitative data requires that this conclusion be made cautiously.

The third question aimed to identify how satisfied the students were with particular sub-domains of collaborative project writing. It was found that they were particularly content that their experience contributed to their English language skills, which was also reflected in the qualitative data collected using the discourse completion task. They often said it gave them the opportunity to edit each other's work, resulting in peer-coaching. This supports the argument that collaborative writing provides an opportunity for immediate feedback [18], and that students become accountable for their own as well as their friends' learning [17]. Nevertheless, it is also important to note the concern about language use expressed by nine students (four female and five male) who responded to the discourse completion task. These students were particularly concerned that the deficiencies in some team members'
English language skills either reduced the quality of work produced or increased the amount of work to be done by other more 'capable' students, resulting in certain amount of distress.

The students were also happy with team skills and practices they acquired during the process of writing their project collaboratively. There were remarks related to conflict resolution and leadership skills. These are particularly important to note since they clearly prepare students for cooperation and negotiation skills they will need in their work places upon graduation [10]. From the phenomenological approach, I can say that my experience teaching collaborative writing over the years resonates with this. At times students in our classes are paired up with those who may have different writing styles and approaches to problem solutions. This observation was also supported by the qualitative data in this study. Some students' concern about clashing opinions in the qualitative data is particularly important to note since it was the most frequently expressed concern. It is also important to note that the female students were comparatively more apprehensive about this, which may be due to stronger personalities among this group of students, an observation that is supported by four female students' reference to personality clashes among the negative aspects of their collaborative project writing experience. Although this is generally a challenge initially, students' acquisition of team skills is facilitated through effective mentoring by the instructor during the project writing process and the presentation of various communication topics in seminars. Nonetheless, the total frequency of concern about clashing opinions (15) in this study indicates that this problem may not be completely eradicated within a 16-week long timeframe. Considering the fact that this was students' very first time engaging in a PBL environment, this may be expected.

Comparison of student perspectives considering the gender factor -as yielded by the quantitative data- showed that the female students were generally more satisfied with the effects of collaborative learning on their English language. This is despite some skepticism expressed in the qualitative data by the female students (4). Yet the female students' comparatively higher satisfaction level was also affected by team-skills. It is possible that the gender-segregated nature of the instruction may have caused this. Females are normally known to have a more sensitive approach to interpersonal communication than males. In the current study, this may as well have played a role in the female students' increased attention to team skills when collaborating to write their project papers. Previous research has also showed that single-gender collaborative groups work to the advantage of female students who seem to be more willing to share and cooperate with each other when faced with unfamiliar tasks [30]. Despite this, other research in the UAE context found that students in mixed-gender groups accomplished the 
task more successfully and achieved better academic results than did the same-gender groups [31]. This likely stemmed from "the synergies and efficiencies of interactive learning in a diverse group of students" [31, p. 433]. With the direction the PI, where this research was undertaken, is taking towards mixed-gender education, this may particularly be promising. Nevertheless, the female students' comparatively higher satisfaction with team-skills appears to be overshadowed by concerns expressed by some students. For example, four students cited personality clashes as a source of discontentment, while nine others mentioned clashing opinions. However, it is possible that these problems challenged them more at the beginning of the course, and many turned into positive experiences with support from the instructor, as is discussed above.

Another commonly mentioned negative aspect was careless work on the part of some students, which was detected seven times in the female students' responses and four times in the male students' responses. This irresponsible attitude indicates a lack of respect for the task at hand as well as for team-members. Earlier research by Iqbal, Velan, O'Sullivan, and Balasooriya [32] also found that similar behaviors including passivity, irresponsibility, and unreliability often created resentment among group members causing an adverse effect on learning. However, Iqbal et. al. [32] also state that these may not necessarily impact interaction. In the case of this current study too, this may be the case due to the collectivist nature of the Emirati culture. It has been noted that members of collectivist cultures tend to refrain from explicit complaints and expressions of dissatisfaction, which may otherwise result in unharmonious relationships [33]. As a member of a collectivist culture, Arabs have been observed to be "soft on people" to avoid losing face, even at the expense of the task at hand [34]. In a previous study conducted on first-year students in the same institution, I also found that students often shunned the face-threatening act of complaint when not satisfied with their team members' quality of work [35]. It is also important to acknowledge the possibility that this very nature of the students in this current study, too, might have resulted in some students' decision to avoid complaint or criticism directed against a process which I -as their instructor-am highly committed to. This may be a reason why only about half of the students responded to the second, voluntary data collection instrument despite the assurance that their responses were to be kept anonymous.

\section{Conclusions and Recommendations for Future Research}

Traditionally perceived as an individual deed, writing in fact can be performed in collaboration with others. Much of writing in real life (in the work-place in particular) is done in this fashion. This has become even more possible thanks to advances in computer technology such as Google Docs which allows several individuals to work on the same draft simultaneously. Writing collaboratively in this manner is particularly important for teams of people who have assembled for project purposes. Project writing incorporates both cooperative and collaborative writing experiences (the differences and the overlaps between the two were described above). Universities aiming to prepare students for real life need to provide authentic learning experiences. In terms of the writing skills they require, this could best done in PBL-friendly learning environments, which are compatible with the social constructivist approaches to teaching and learning. In such environments, students have the opportunity to present their own ideas as well as hear and reflect on their teachers' and peers' ideas, helping them to change or reinforce conceptions [36], acquire new skills, and reinforce already existing ones. Collaborative project writing also appears to be compatible with collectivist cultures, an example of which is the Emirati culture to which the participants of this study belonged. This study showed that first-year students in an Emirati university were quite satisfied with their collaborative project writing experience in an English course, often reporting benefits such as social and language skills development along with the utilization of higher order thinking skills. Yet they also expressed concerns about certain aspects including less able/responsible students' tendencies to rely on others, conflicts, and time-management problems. However, these challenges can be circumvented if dealt with in pedagogically and culturally sensitive ways. Such an approach can result in challenges being imbued with new understandings and growth.

This study had some limitations, one of which was related to its relatively small sample size. It included only sixty-four students from the researcher's own classes. Future researcher could increase this sample size by including students from a higher number of classes taught by different instructors. This would help not only increase generalizability of the results within the same institution (if not in wider contexts), but also reduce any potential of researcher bias as well as skewed student responses. The latter is of particular importance considering the possibility that the student responses in this study may have been influenced by their attitude towards the researcher being their class teacher. Students' collaborative writing experiences could also be investigated from the cross-cultural perspective. This would help elucidate cultural factors that play a role in students' engagement in and satisfaction with collaborative learning experiences. This may also increase our understanding of student dissatisfaction in such learning situations. Future researchers could also replicate this study in co-educational contexts to identify whether student perceptions are influenced by their collaborative writing experiences in 
mixed-gender teams.

\section{REFERENCES}

[1] Sarvaiya, M. (2013). Human communication. Mumbai: Lulu.

[2] Okita, S. (2012). Social interaction and learning. In N. M. Seel (Ed.). Encyclopedia of the sciences of learning (pp. 3104-3107). New York, NY: Springer.

[3] Vygotsky, L. (1978). Mind in society. Cambridge, MA: Harvard University Press.

[4] Storch, N. (2016). Collaborative writing. In R. M. Manchón \& P. K. Matsuda (Eds.). Handbook of second and foreign language writing (pp. 387-406). Boston and Berlin: Walter de Gruyter.

[5] Nunn, R., Brandt, C., \& Deveci, T. (2016). Project-based learning as a holistic learning framework: integrating 10 principles of critical thinking. The Asian ESP Journal Special Issue, 12(2), 9-53.

[6] Nunn, R., Deveci, T., \& Salih, H. E. S. B. (2015). Phenomenological views of the development of critical argumentation in learners' discourse. The Asian EFL Journal Professional Teaching Articles, 85, 90-116.

[7] Dobao, A. F., \& Blum, A. (2013). Collaborative writing in pairs and small groups: Learners' attitudes and perceptions. System, 41, 365-378.

[8] Diseth, A. (2007). Students' evaluation of teaching approaches to learning, and academic achievement. Scandinavian Journal of Educational Research, 51(2), 185-204.

[9] Howard, R. M. (2001). Collaborative pedagogy. In G. Tate, A. Rupiper, \& K. Schick (Eds.). A guide to composition pedagogies (pp. 54-70). Oxford: Oxford University Press.

[10] Speck, B. W. (2002). Facilitating students' collaborative writing. California: Jossey-Bass.

[11] Vanderberg, P., Hum, S., \& Clary-Lemon, J. (2006). Critical introduction. In P. Vanderberg, S. Hum, \& J. Clary-Lemon (Eds.). Relations, locations, positions: Composition theory for writing teachers (pp. 1-20). Urbana, IL: NCTE.

[12] van Merriënboer, J. J. G., \& de Bruin, A. B. H. (2014). Research paradigms and perspectives on learning. In J. M. Spector, M. D. Merrill, J. Elen, \& M. J. Bishop (Eds.). Handbook of research on educational communications an technology (4 ${ }^{\text {th }}$ ed.) (pp. 21-29). New York: Springer.

[13] Smith, B. L., \& MacGregor, J. T. (1992). What is collaborative learning. In A. Goodsell, M. Maher, V. Tinto, B. L. Smith, \& J. Macgregor (Eds.). Collaborative learning. A sourcebook for higher education (pp. 10-30). Pennyslvania State University: National Center on Postsecondary Teaching, Learning and Assessment.

[14] Ndon, U. (2011). Hybrid-context instructional model: The internet and the classrooms: the way teachers experience it. The USA: Information Age Publishing Inc.
[15] Knowles, M. (1975). Self-directed learning: A guide for learners and teachers. New York: Association Free Press.

[16] Talib, T., \& Cheung, Y. L. (2017). Collaborative writing in classroom instruction: A synthesis of recent research. The English Teacher, 46(2), 43 - 57.

[17] Fong, L. S. (2012). Benefits of collaborative writing for ESL advanced diploma students in the production of reports US-China Education Review, 4, 396-407.

[18] Grief, S. (2007). Collaborative writing. London: the National Research and Development Centre for Adult Literacy and Numeracy.

[19] Shea, J. H. (1995) Problems with collaborative learning. Journal of Geological Education, 43(4), 306-308.

[20] Markham, T. Larmer, J., \& Ravitz, J. (2003). Project based learning handbook: A guide to standards-focused project based learning for middle and high school teachers: Buck Institute for Education.

[21] Boss, S., \& Krauss, J. (2014). Reinventing project-based learning: Your field guide to real-world projects in the digital age ( $2^{\text {nd }}$ ed.). Eugene, OR: International Society for Technology in Education.

[22] Prince, M. J., \& Felder, Richard M. (2006). Inductive teaching and learning methods: Definitions, comparisons, and research bases. Journal of Engineering Education. 95, 123-138.

[23] Conforti, J., \& Rasmussen, B. (n.d.). Hands on writing! In a project based environment. Retrieved from https://www.academia.edu/720947/Hands_on_Writing_C ollaborative Writing in a Project Based Environment? auto $=$ download

[24] Santoro, F. M., Borges, M. R., \& Santos, N. (2003). Experimental findings with collaborative writing within a project-based scenario. In M. Llamas-Nistal, M. J. Fernandez-Iglesias, \& L. E. Anido-Rifon (Eds.). Computers and education: Towards a lifelong learning society (pp. 179-190). Dordrecht: Springer.

[25] Deveci, T., \& Nunn, R. (2018). COMM151: A project-based course to enhance engineering students' communication skills. The Journal of Teaching English for Specific and Academic Purposes, (in press)

[26] Miles, M. B., \& Huberman, A. M. (1994). Qualitative data analysis: An expanded sourcebook (2nd ed.). Thousand Oaks, CA: Sage Publications.

[27] Nguyen, P-M., Terlouw, C., \& Pilot, A. (2005). Cooperative learning vs. Confucian heritage culture's collectivism: Confrontation to reveal some cultural conflicts and mismatch. Asia Europe Journal, 3(3), 403-419.

[28] Holmes, G., Sherman, T., \& Williams-Green, J. (1997). Culture as a decision variable for designing computer software. Educational Technology Systems, 26(1), 3-18.

[29] Grunspan, D. Z., Eddy, S. L., Brownell, S. E., Wiggins, B. L., Crowe, A. J., \& Goodreau, S. M. (2016). Males' under-estimated academic performance of their female peers in undergraduate biology classrooms. PLoS ONE, 11(2): e0148405. https://doi.org/10.1371/journal.pone.0148405 
[30] Chennabathni, R., \& Rejskind, G. (1998). Gender issues in collaborative learning. Canadian Woman Studies, 17(4), 44-46.

[31] Cen, L., Ruta, D., Powell, L., \& Ng, J. (2014). Does gender matter for collaborative learning? IEEE International Conference on Teaching, Assessment, and Learning for Engineering, 433-440, New Zealand.

[32] Iqbal, M., Velan, G. M., O’Sullivan, A, J., \& Balasooriya, C. (2016). Differential impact of student behaviours on group interaction and collaborative learning: Medical students' and tutors' perspectives. BMC Med Educ., 16(1), 217.

[33] Reisinger, T., \& Turner, L. (1999). A cultural analysis of
Japanese tourists: Challenges for Tourism Marketers. European Journal of Marketing, 33 (11/12), 1203-27.

[34] Al-Omari, J. (2008). Understanding Arab culture: a practical cross-cultural guide to working in the Arab world. Oxford: How to Books.

[35] Deveci, T. (2015). Freshman students' emotional intelligence and team-work satisfaction levels. Yükseköğretim Dergisi [Journal of Higher Education], 5(1), 35-43.

[36] Brooks, M. G., \& Brooks, J. G. (1999). The courage to be constructivist. Educational Leadership, 57(3), 18-24. 